\title{
TRABALHANDO OS OSSOS DO CORPO HUMANO NA EDUCAÇÃO INFANTIL: UM RELATO DE EXPERIÊNCIA
}

\author{
TRABAJANDO LOS HUESOS DEL CUERPO HUMANO EN LA EDUCACIÓN \\ INFANTIL: UN RELATO DE EXPERIENCIA
}

\section{WORKING BONES OF THE HUMAN BODY IN CHILD EDUCATION: A REPORT OF EXPERIENCE}

\author{
Andreia Pires DIAS ${ }^{1}$ \\ Renata de Oliveira GALVÃO ${ }^{2}$ \\ Edvonete Souza de ALENCAR ${ }^{3}$
}

RESUMO: O presente relato de experiência tem por objetivo apresentar o projeto desenvolvido no Estágio Supervisionado que teve o intuito de propiciar à criança conhecer o esqueleto humano, reconhecendo-o e valorizando-o como fonte importante para o seu desenvolvimento integral (físico, motor, social, cultural, entre outros). O referido projeto delineou-se na disciplina Gestão e na docência da educação Infantil II na Universidade Federal da Grande Dourados, sendo essa voltada para a formação da criança na instituição da Educação Infantil de quatro a cinco anos. Teve como metodologia a Pesquisa Bibliográfica, Pesquisa Documental e Pesquisa de Campo. O desenvolvimento abarcou atividades lúdicas para que as crianças compreendessem como é formado o esqueleto humano levando-as a interagirem de modo significativo e prazeroso. Conclui-se que o projeto foi de suma importância porque alcançou o objetivo proposto, bem como, porque, por meio do estágio, pode-se conhecer mais de perto o universo da Educação Infantil e aliar a teoria acadêmica à prática propriamente dita.

PALAVRAS-CHAVE: Estágio supervisionado. Corpo humano. Educação infantil. Esqueleto.

RESUMEN: El presente relato de experiencia tiene por objetivo presentar el proyecto desarrollado en la Etapa Supervisionada que tuvo el propósito de propiciar al niño conocer el esqueleto humano, reconociéndolo y valorándolo como fuente importante para su desarrollo integral (físico, motor, social, cultural, entre otros). El referido proyecto se delineó en la disciplina Gestión y en la docencia de la educación Infantil II en la Universidad Federal de la Grande Dourados, siendo esta volcada para la formación del niño en la institución de Educación Infantil de cuatro a cinco años. En el caso de las mujeres, El desarrollo abarcó actividades lúdicas para que los niños

\footnotetext{
${ }^{1}$ Universidade Federal da Grande Dourados (UFGD), Dourados - MS - Brasil. Licencianda do curso de Pedagogia. E-mail: andreiapclaro@gmail.com

${ }^{2}$ Universidade Federal da Grande Dourados (UFGD), Dourados - MS - Brasil. Licencianda do curso de Pedagogia. E-mail: regalvao95@hotmail.com

${ }^{3}$ Universidade Federal da Grande Dourados (UFGD), Dourados - MS - Brasil. Prof ${ }^{a}$ Adjunta da Faculdade de Educação. Doutora em Educação Matemática pela PUC-SP. E-mail: edvonete.s.alencar@hotmail.com
} 
comprendieran cómo se forma el esqueleto humano llevándolos a interactuar de modo significativo y placentero. Se concluye que el proyecto fue de suma importancia porque alcanzó el objetivo propuesto, así como porque, por medio del estadio, se puede conocer más de cerca el universo de la Educación Infantil y aliar la teoría académica a la práctica propiamente dicha.

PALABRAS CLAVE: Etapa supervisada. Cuerpo humano. Educación infantil. Esqueleto.

ABSTRACT: The purpose of this experience report is to present the project developed in the Supervised Stage, which aimed to enable the child to know the human skeleton, recognizing and valuing it as an important source for its integral development (physical, motor, social, cultural, among others). This project was outlined in the discipline of Management and teaching of Infantile Education II at the Federal University of Grande Dourados, which focused on the formation of the child in the institution of Early Childhood Education from four to five years. The methodology was Bibliographic Research, Documentary Research and Field Research. The development involved playful activities so that the children understood how the human skeleton is formed causing them to interact in a meaningful and pleasurable way. It is concluded that the project was of great importance because it reached the proposed objective, as well as, because through the stage, one can know more closely the universe of Infantile Education and ally the academic theory to the practice itself.

KEYWORDS: Supervised internship. Human body. Child education. Skeleton.

\section{Introdução}

Quando o relógio bate a uma, Todas as caveiras saem da tumba; Tumbalacatumba tumba ta Tumbalacatumba tumba ta (RUBES ARJONA; VALENTINO GUZZO, 2003)

A música Tumbalacatumba normalmente presente no cenário infantil nos leva a reflexões iniciais com a temática de nosso relato de experiência sobre o conhecimento dos ossos do corpo humano e como essa abordagem pouco explorada nesse segmento de ensino é importante para a formação dos alunos. As cantigas como estas que são coreografadas despertam a atenção e animam muito as crianças, estimulando habilidades como noção de tempo, memória, linguagem corporal, memória, expressão, vocabulário, ritmo, entre tantos outros aspectos importantes na fase de crescimento. A dança, as caveiras trazem um momento lúdico com regras simples que servem para quebrar o gelo no início da aula. Em cada estrofe, o horário muda e as caveiras (que são 
os personagens principais) fazem alguma atividade diferente, desta forma as crianças reproduzem as ações dos personagens, dançando, representando e fazendo mímicas.

Vemos que a Educação Infantil é um direito da criança conforme a Constituição Federal do Brasil de 1988. O Art. 205 refere-se à educação como direito de todos e dever do Estado e da família, promovida e incentivada com a colaboração da sociedade, visando ao pleno desenvolvimento da pessoa, seu preparo para o exercício da cidadania e sua qualificação para o trabalho, sendo um dever do Estado de garantir essa educação conforme o Art. 208, inciso IV, da Constituição Federal.

As definições curriculares estão previstas nas Diretrizes Curriculares Nacionais para a Educação Infantil (DCNEI), Resolução CNE/CEB n. 05/2009. Sobre os aspectos curriculares destacamos o Artigo $3^{\circ}$ das DCNEI que afirma:

\begin{abstract}
Art. $3^{\circ} \mathrm{O}$ currículo da Educação Infantil é concebido como um conjunto de práticas que buscam articular as experiências e os saberes das crianças com os conhecimentos que fazem parte do patrimônio cultural, artístico, ambiental, científico e tecnológico, de modo a promover o desenvolvimento integral de crianças de 0 a 5 anos de idade. (BRASIL/CNE/CEB, 2009)
\end{abstract}

Visando essa prática de saberes e experiências na educação infantil, o professor deve se preocupar em realizar um conjunto de procedimentos que envolvam e possam despertar o conhecimento nas crianças, auxiliando-as para que vivenciem os saberes advindos das ciências, das artes e da cultura em geral.

Neste sentido, o projeto de Estágio Supervisionado em Educação Infantil II, aqui apresentado em forma de relato de experiência, teve por objetivo propiciar à criança o conhecimento do esqueleto humano, reconhecendo-o e valorizando-o como fonte importante para o seu desenvolvimento integral (físico, motor, social, cultural, entre outros).

A metodologia do projeto abarcou a Pesquisa Bibliográfica, por aportes teóricos que tratam da temática, Pesquisa Documental, pelos documentos e leis que norteiam a Educação Infantil e Pesquisa de Campo que teve como campo empírico o Centro de Educação Infantil Municipal (CEIM) situado na zona urbana da cidade de Dourados/MS.

Destaca-se que o referido CEIM, que tem como filosofia firmar o compromisso com a formação do cidadão, tendo metas de qualidade para contribuir para as crianças terem um desenvolvimento integral, sendo capaz de crescerem como cidadãos com direitos à infância reconhecida. 
A turma de Educação Infantil em foco foi do turno matutino composta por (vinte) 20 crianças com a faixa etária de quatro a cinco (4-5) anos, a maioria delas vindas de família com dificuldades financeiras.

Considera-se que o projeto desenvolvido tem relevância científica tendo em vista que ampliou as discussões a respeito das práticas pedagógicas voltadas à relação: criança/conhecimento da sua estrutura óssea corporal. Acredita-se que também é de relevância social, porque o trabalho possibilitou a interatividade entre as crianças, a socialização destas, bem como levou à compreensão de como elas podem interagir com o mundo que as rodeiam por meio dos seus corpos.

\section{A arte de ensinar}

Ensinar é criar possibilidades para a produção ou construção do saber (FREIRE, 1996, p. 21). Quando vivemos a autenticidade exigida pela prática de ensinar-aprender participamos de uma experiência total, diretiva, política, ideológica, gnosiológica, pedagógica, estética e ética, em que a beleza deve achar-se de mãos dadas com a decência e com a serenidade (FREIRE, 1996, p. 24). O ensinar exige mais do professor do que do aluno, ensinar envolve aceitação do novo, exige reflexão crítica, bom senso, humildade, tolerância, alegria e esperança, traz curiosidade, pois ensinar não é transferir conhecimento, é uma especificidade humana que exige segurança, competência profissional, comprometimento e compreender que a educação é uma forma de intervenção no mundo (FREIRE, 1996). Neste sentido, o preparo do docente e o zelo com a ministração das aulas é fundamental para corroborar no aprendizado e na fixação dos conteúdos. $\mathrm{O}$ ensinar abarca fontes, princípios e ludicidade. O brincar traz inúmeras manifestações que colaboram para o desenvolvimento cognitivo, motor e social da criança.

Para montar o projeto de ação pedagógica primeiramente é preciso conhecer os alunos com os quais será desenvolvido o projeto, ver a realidade em que vivem e os conhecimentos que já possuem, assim vemos uma das possibilidades de ocorrer aprendizagem. A teoria da aprendizagem de Ausubel (1982) propõe que os conhecimentos prévios dos alunos sejam valorizados, para que possam construir estruturas mentais utilizando como meio mapas conceituais que permitem descobrir e redescobrir outros conhecimentos, caracterizando, assim, uma aprendizagem prazerosa e eficaz. 
A anatomia e a fisiologia são temas ricos que poderão ser abordados durante todo período letivo, claro que a fisiologia se aplica mais ao ensino fundamental II em diante, mas não impede que seja abarcado já na educação infantil. Ao estudar anatomia, o profissional deverá estudar e buscar bibliografia especializada, a qual se acredita ser mais evidenciada nos cursos da área da saúde. Neste viés, o estudo foi diferenciado por já ter conhecimento em anatomia e fisiologia, haja vista que a formação inicial na área da enfermagem de uma das autoras corroborou para o ensino sobre os ossos, proporcionando a todos os cidadãos os conhecimentos e oportunidades de desenvolvimento de capacidades necessárias para se orientarem em uma sociedade complexa, compreendendo o que se passa à sua volta e tomando posição e intervindo em sua realidade (CHASSOT, 2003).

De acordo com os Parâmetros Curriculares Nacionais (PCN), é importante o estudo do ser humano considerando o corpo como um todo dinâmico, que interage com o meio em sentido amplo, que o meio onde o corpo está inserido de alguma forma pode alterar a integridade e o funcionamento de suas partes, podendo afetar a saúde humana e consequentemente a qualidade de vida. Conhecendo o corpo humano, pode contribuir para a formação da integridade pessoal e da autoestima, da postura de respeito a si próprio e aos outros e para o entendimento da saúde como um valor pessoal e social e para a compreensão da sexualidade humana sem preconceitos e respeitando as diferenças (PCN, 1996).

O lúdico traz uma perspectiva de aprendizado com a qual a criança aprende, interage, exemplifica de forma prazerosa. Por meio das atividades lúdicas foi possível estimular a criatividade das crianças, o trabalho em grupo e suas habilidades, mesmo montando algumas regras, pois são formas diferentes e divertidas que dão o prazer. Friedman (1996, p. 41) considera que:

Os jogos lúdicos permitem uma situação educativa cooperativa e interacional, ou seja, quando alguém está jogando está executando regras do jogo e, ao mesmo tempo, desenvolvendo ações de cooperação e interação que estimulam a convivência em grupo.

De acordo com Santos (1999), para a criança "brincar é viver". Sendo assim, tudo gira em torno do brincar e se divertir. E através desse desejo que as crianças possuem vai ser trabalhado o corpo humano e as suas especificidades. Dessa forma lúdica é possível ensinar conteúdos sobre os quais as crianças possuem pouco conhecimento. 


\section{A criança e a interação em atividades lúdicas para o reconhecimento do esqueleto humano}

Um dos pontos imprescindíveis para o desenvolvimento do projeto foi a necessidade de criar condições para promover o desenvolvimento da criança, de forma que tudo o que esta visse, vivenciasse, aprendesse, pudesse levar adiante, facilitando o seu futuro e seus próximos aprendizados.

Para Vygotsky (1984), é no caminho entre as práticas que uma criança já domina e as atividades que ainda depende de ajuda que poderá se desenvolver mentalmente por meio da interação e da troca de experiências para então ser avaliada em seu desempenho.

Neste viés, o surgimento do projeto se deu a partir do estágio realizado na Educação Infantil I, na qual trabalhamos os diferentes tipos de texturas e durante a aplicação do mesmo surgiu a ideia de se trabalhar o corpo humano. Durante a observação na gestão e em sala de aula, esse objetivo foi confirmado ao depararmos com crianças que tinham dificuldade em saber o que era o esqueleto humano, traziam consigo o nome de "caveira" e tinham como algo do "mal". Foi realizado com os alunos um trabalho de conscientização, das funções e importância do esqueleto humano e da desmistificação da caveira como símbolo do mal, assim foi possível identificar as partes do corpo humano para familiarizar-se com elas, valorizando suas funções; conscientizar sobre os cuidados e higiene do corpo para termos saúde; desenvolver a coordenação motora ampla nas atividades; demonstrar equilíbrio e lateralidade deslocando-se no espaço físico da escola; participar das atividades práticas sobre o cuidado e higiene com o corpo; identificar alimentos derivados do leite que fortalecem os ossos; esses foram os objetivos do projeto, além de abordar outros temas relacionados como as diferenças.

Segundo Hernandez (1998), os projetos de trabalho contribuem para uma (re)significação dos espaços de aprendizagem de tal forma que eles se voltem para a formação de sujeitos ativos, reflexivos, atuantes e participantes. Nosso objetivo foi trabalhar com o corpo humano, em especial os ossos, explicamos como somos concebidos e como os nossos ossos são formados. As crianças não entendem o que faz com que fiquemos em pé. Sendo assim, cada criança fez a sua própria palpação e observou seu colega, contando quantos dedos há nas mãos e qual o maior osso do corpo, além disso, tratou-se a importância de uma boa alimentação rica em cálcio, cuidados com uso exagerado de alimentos prejudiciais aos ossos como refrigerantes, por exemplo, corroborando para uma aula dinâmica e prazerosa com amostras de alguns 
alimentos derivados do leite para a manutenção dos ossos. Posteriormente, foi trabalhado letramento, utilizando a palavra "OSSO".

O ápice do projeto foi a construção de um esqueleto humano com hastes flexíveis. A avaliação se baseou em questionários como: - O que temos dentro do nosso corpo e que nos faz ficar em pé? Quantos ossos temos nas mãos (falanges)? Podemos ocupar o mesmo espaço que meu colega está? Quais os alimentos que devemos consumir para fortalecer os ossos? Qual é o maior osso do corpo humano? Ao final, as crianças tiveram bom aproveitamento nas aulas, expondo seus cartazes com a maquete dos ossos do corpo humano.

\section{Construção do esqueleto}

Como exercício de fixação foi confeccionado um esqueleto usando hastes flexíveis numa folha A4. Nela já havia sido colado previamente um xérox de crânio na parte superior e de uma pelve na parte inferior. Delineamos com lápis os locais que seriam colados os cotonetes com cola siliconada de secagem mais rápida.

Cada criança teve a oportunidade de construir o seu próprio esqueleto, todas tiveram ajuda nos momentos em que mais sentiram dificuldades. A atividade ocorreu conforme o planejado, porém, foi bastante divertida e teve a participação de todos os alunos da sala que ficaram muito empolgados com as atividades diferenciadas do cotidiano.

Tivemos o auxílio e a participação da professora regente que, prontamente, ajudou-nos como mostra a imagem a seguir com o trabalho final.

Figura 1: Atividade com o esqueleto

Fonte: PPPPPP

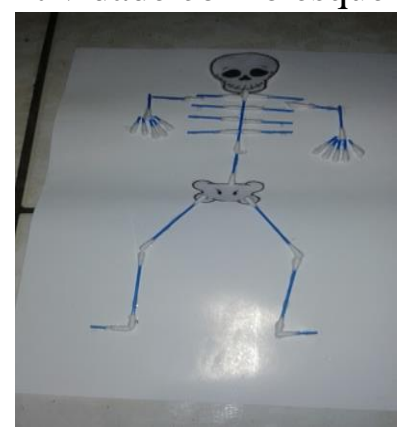


Figura 2: Confeccionando o esqueleto

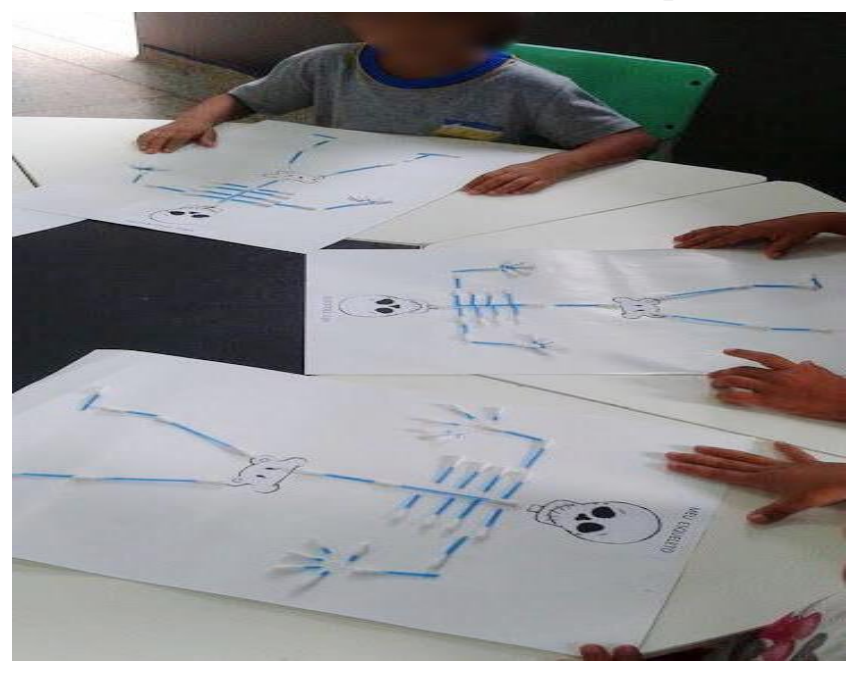

Fonte: PPPPPP

Figura 3: Cada criança mostrando seu esqueleto

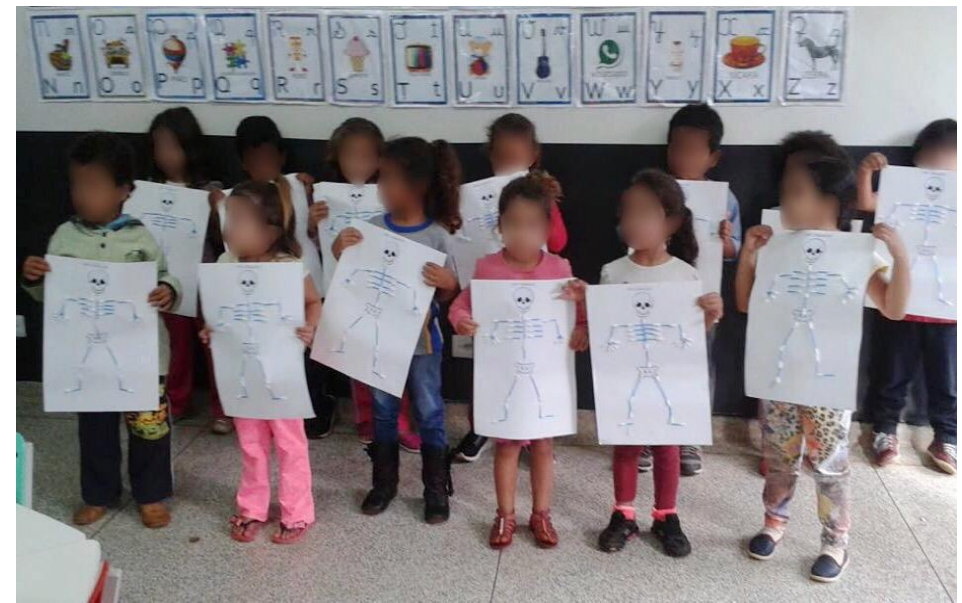

Fonte: PPPPPPP

\section{Nossas considerações}

Trabalhar a música, na educação infantil como possibilidade de aprendizado, trouxe grandes oportunidades de comunicação, socialização, estímulo de habilidades como noção de tempo, memória, linguagem corporal, memória, expressão, vocabulário, ritmo, entre outros. Com a experiência vivida no estágio, foi possível notar que as crianças que viviam naquela região não eram estimuladas por seus familiares, os assuntos que sabiam eram aqueles que haviam sido ensinados pela professora regente. 
Através de estímulos é possível abordar outros temas relacionados ao corpo, como ossos, saúde, higiene, identidade e também diferenças raciais. Então, com o lúdico e muita persistência, foi possível desconstruir a ideia de caveira do mal que as crianças tinham sobre o esqueleto. Foi fundamental, para a realização das atividades lúdicas, partir da realidade e necessidades dos alunos. De acordo com Borba (2006, p. 41), "a brincadeira é um lugar de construção de culturas fundado nas interações sociais entre as crianças".

As aulas ministradas para as crianças causaram grande curiosidade sobre o tema e foi possível notar que elas realmente ficaram preocupadas com o cuidado do corpo humano, descobrindo que havia ossos por dentro, os quais mantêm o corpo humano em pé e este é equilibrado através da coluna vertebral. Perceberam que, para se ter um corpo saudável, é necessário, primeiramente, ter uma alimentação saudável, sem exagerar nos doces e refrigerantes, praticar atividades físicas e sempre manter uma boa higiene através de cuidados com o corpo e com a boca.

\section{REFERENCIAS}

AUSUBEL, D. P. A aprendizagem significativa: a teoria de David Ausubel. São Paulo: Moraes, 1982.

BORBA, A. M. O brincar como um modo de ser e estar no mundo. In: BRASIL. Ministério da Educação. Secretaria de Educação Básica. Ensino Fundamental de nove anos: Orientações para a inclusão de crianças de seis anos de idade. 2. ed. Brasília, 2006.

BRASIL. Senado Federal. Constituição da República Federativa do Brasil. Texto Constitucional de 5 de outubro de 1988, Brasília: Senado Federal, Subsecretaria de Edições Técnicas, 1988.

CHASSOT, A. Catalisando transformações na educação. Ijuí: Editora Unijuí, 1993.

DIAS, A. P. Os ossos do corpo humano. Dourados, 2017.

DOURADOS. Conselho Municipal de Educação. Deliberação/COMED No 080, de 16/06/2014. Dispõe sobre a Organização e o Funcionamento da Educação Básica nas etapas da Educação Infantil e Ensino Fundamental, no Sistema Municipal de Ensino de Dourados e dá outras providências. Dourados: COMED, 2014.

FREIRE, P. Pedagogia da autonomia: saberes necessários à prática educativa. São Paulo: Paz e Terra, 1996. - Coleção Leitura 
FRIEDMANN, A. Brincar, crescer e aprender: o resgate do jogo infantil. São Paulo: Moderna, 1996.

BRASIL. Lei Nº. 9394, de 20 de dezembro de 1996. Lei de Diretrizes e Bases da Educação Nacional. Brasília, 1996.

MINISTÉRIO DA EDUCAÇÃO E DO DESPORTO. Secretaria de Educação Fundamental. Departamento da Política de Educação Fundamental. Departamento da Coordenadoria Geral de Educação Infantil. Referencial Curricular Nacional para a Educação Infantil. Volumes 1, 2 e 3. Brasília: MEC/SEF/DPEF/COEDI, 1998.

MINISTÉRIO DE EDUCAÇÃO. Conselho Nacional de Educação. Câmara de Educação Básica. Resolução CNE/MEC, Nº 5, de 17 de dezembro 2009. Diretrizes Curriculares Nacionais para a Educação Infantil. Brasília: D.O.U. de 18 de dezembro de 2009.

SANTOS, S. M. P. dos (Org.). Brinquedo e infância: um guia para pais e educadores. Rio de Janeiro: Vozes, 1999.

\section{Como referenciar este artigo}

DIAS, Andreia Pires.; GALVÃO, Renata de Oliveira.; ALENCAR, Edvonete Souza de. Trabalhando os ossos do corpo humano na educação infantil: um relato de experiência. Temas em Educação e Saúde, Araraquara, v.14, n.1, p. 188-197, jan./jun., 2018. EISSN: 2526-3471. DOI: 10.26673/rtes.v14.n1.2018.10838

Submetido em: 05/02/2018

Aprovado em: 05/05/2018 